\title{
Association of BAFF with PI3K/Akt/mTOR signaling in lupus nephritis
}

\author{
FENGMEI GE* , FANGFANG WANG* ${ }^{*}$ XIUQING YAN, ZHAO LI and XUEBIN WANG \\ Department of Rheumatology, Binzhou Medical University Hospital, Binzhou, Shandong 256603, P.R. China
}

Received October 28, 2016; Accepted June 16, 2017

DOI: $10.3892 / \mathrm{mmr} .2017 .7367$

\begin{abstract}
Systemic lupus erythematosus is a connective tissue disease characterized by autoimmune inflammation, which leads to specific and nonspecific immune disorders with the formation of various autoantibodies by activated B cells. B-cell-activating factor (BAFF) is secreted by macrophages and activated $\mathrm{T}$ cells, and is responsible for the proliferation, maturation and differentiation of B cells. However, the mechanism of BAFF involvement in lupus nephritis (LN) remains unclear. The aim of the present study was to investigate the association between BAFF and phosphoinositide 3-kinase/protein kinase $\mathrm{B} /$ mammalian target of rapamycin (PI3K/Akt/mTOR) signaling in order to elucidate the pathogenesis of LN. In the present study, 18 patients with LN and 20 controls were included. The clinical data were analyzed and plasma levels of BAFF were measured using an ELISA. The mRNA and protein levels of BAFF, phosphorylated (p)-PI3K, p-Akt and p-mTOR in kidney tissues were measured using reverse transcription-quantitative polymerase chain reaction (RT-qPCR) and western blotting. Plasma BAFF levels were significantly increased in patients with LN compared with the controls $(\mathrm{P}<0.001)$. mRNA and protein levels of BAFF, p-PI3K, p-Akt and p-mTOR in kidney tissue were significantly increased in patients with LN compared with the controls (all $\mathrm{P}<0.001)$. mRNA and protein levels of BAFF in the kidney tissues of patients with LN were positively correlated with the levels of p-PI3K, p-Akt and p-mTOR. The results of the present study revealed a correlation between BAFF and the $\mathrm{PI} 3 \mathrm{~K} / \mathrm{Akt} / \mathrm{mTOR}$ signaling pathway, and it is hypothesized that they are involved in the pathogenesis of LN.
\end{abstract}

Correspondence to: Professor Xuebin Wang, Department of Rheumatology, Binzhou Medical University Hospital, 661 Huanghe 2nd Road, Binzhou, Shandong 256603, P.R. China

E-mail: wxbbyfy@163.com

*Contributed equally

Key words: B-cell-activating factor, lupus nephritis, phosphoinositide 3-kinase/protein kinase $\mathrm{B} /$ mammalian target of rapamycin signaling

\section{Introduction}

Systemic lupus erythematosus (SLE) is a chronic autoimmune disease that can cause multiorgan and multisystemic damage through the production of various autoantibodies, and the development of lupus nephritis (LN) is one of the most important factors influencing prognosis in SLE (1-3). A number of factors, including genetic, hormonal, environmental and presence of drugs, can influence the development of LN, which leads to breakdown of immune tolerance and organ dysfunction (3). Although the precise pathogenesis of LN remains to be elucidated, numerous clinical and animal experiments have demonstrated that B cells serve an important function in the pathogenesis of LN (4-6).

B-cell-activating factor (BAFF), member of the tumor necrosis factor superfamily, is an important B cell-proliferation and maturation factor, and is secreted by a variety of cell types including monocytes, malignant B cells, macrophages, neutrophils and activated T lymphocytes (7-9). BAFF can act by binding a transmembrane activator coupled with a calcium modulator, a cyclophilin ligand interactor transmembrane activator and a calcium signal-modulating cyclophilin ligand interactor, the BAFF receptor (BAFF-R) or the B cell maturation protein, which are expressed on stimulated B cells (10). The binding of BAFF to a receptor induces the proliferation and differentiation of B cells, which serves a vital role in immunoglobulin class switching (11). Excessive amounts of BAFF result in an abnormal autoimmune response mediated by activated B cells (12). In addition, the overexpression of BAFF not only causes B cell proliferation, but also produces a lupus erythematosus-like syndrome in mice; however, the development of lupus can be delayed in the SLE-spontaneous mouse model if the mice are treated with a BAFF inhibitor (13-15).

The phosphatidylinositol 3-kinase (PI3K) P1108 isoform enhances the BAFF-mediated cellular survival and maturation of B cells (16), and this result indicates an important role for the PI3K/protein kinase B (Akt) signaling pathway in response to BAFF stimulation. Mammalian target of rapamycin (mTOR) is a serine-threonine kinase that is the main downstream target of PI3K/Akt. mTOR can regulate a variety of cellular responses in mammalian cells, including cellular growth, energy availability and protein synthesis (17). $\mathrm{PI} 3 \mathrm{~K} / \mathrm{Akt} / \mathrm{mTOR}$ activation serves a vital role in the signaling pathways involved in the inhibition of apoptosis, cell proliferation and expression of inflammatory cytokines (18). Previous 
studies have demonstrated that the PI3K/Akt/mTOR signaling pathway and BAFF/BAFF-R mediated signaling is involved in the pathogenesis of collagen-induced arthritis rats $(19,20)$. It is unknown whether BAFF is involved in the development of LN via regulation of the PI3K/Akt/mTOR pathway. The present study investigated the association between BAFF and $\mathrm{PI} 3 \mathrm{~K} / \mathrm{Akt} / \mathrm{mTOR}$ signaling in order to investigate the pathogenesis in LN.

\section{Materials and methods}

Patient selection. A total of 18 patients (1 man and 17 women) who fulfilled the criteria for LN at Binzhou Medical University Hospital (Binzhou, China) and 20 controls were recruited into the present study. Individuals (6 men and 14 women) aged between 25 and 65 years old who underwent side nephrectomy for renal benign tumors were recruited as controls between December 2014 and December 2015. Laboratory test data including the concentration of complement proteins $\mathrm{C} 3$ and $\mathrm{C} 4$, proteinuria/24 $\mathrm{h}$ and presence of antinuclear, anti-Smith, anti-ribonucleoprotein and anti-double-stranded DNA antibodies were collected and are exhibited in Table I. The above indexes in the control group were within the normal range. Patients and controls included in the present study were excluded for primary and secondary nephropathies, including Henoch-Schonlein purpura nephritis, diabetic nephropathy and hypertensive nephropathy. The kidney tissue of the patients with LN was obtained by renal biopsy. The control tissue was normal renal tissue, taken from a site far removed from that of the renal tumor. The present study was approved by the Ethics Committee of Binzhou Medical University Hospital (Binzhou, China). All the subjects were fully informed about the characteristics and purpose of the present study, and gave informed consent.

Determination of plasma BAFF levels. Plasma BAFF levels were detected by ELISA using the human BAFF kit (cat. no. BPE10132; Shanghai Langton Biotechnology, Co., Ltd., Shanghai, China). According to the manufacturer's protocol, the precoated microplate was covered with capture antibody and incubated for $2 \mathrm{~h}$ following sample addition at room temperature. Following four washes, BAFF conjugate (200 $\mu \mathrm{l} /$ well) was added and agitated gently on a shaker for $30 \mathrm{~min}$ at room temperature. The absorbance was measured on a microplate reader at $450 \mathrm{~nm} 10 \mathrm{~min}$ following the addition of the stop solution for terminating the reaction.

$R N A$ isolation and reverse transcription-quantitative polymerase chain reaction ( $R T-q P C R)$. Frozen kidney tissue stored at $-80^{\circ} \mathrm{C}$ was sectioned (100- $\mu \mathrm{m}$ thick) on a cryostat. RNA was extracted from frozen kidney tissue samples using the RNAiso Plus (cat. no. 9108; Takara Bio, Inc., Otsu, Japan), according to the manufacturer's protocol. RNA $(1 \mu \mathrm{g})$ was reverse transcribed into cDNA using the PrimeScript ${ }^{\mathrm{TM}}$ RT reagent kit (cat. no. RR037A; Takara Bio Inc., ). qPCR was carried out on a Real-Time PCR System (Bio-Rad Laboratories, Inc., Hercules, CA, USA) using the SYBR ${ }^{\circledR}$ Premix Ex Taq $^{\mathrm{TM}}$ II (cat. no. RR820A, Takara Bio Inc.). Thermocycling conditions were as follows: Initial 1 cycle at $95^{\circ} \mathrm{C}$ for $30 \mathrm{sec}$, followed by 40 cycles at $95^{\circ} \mathrm{C}$ for $5 \mathrm{sec}$ and at $60^{\circ} \mathrm{C}$ for $30 \mathrm{sec}$. All PCR
Table I. Clinical characteristics and laboratory results of patients with $\mathrm{LN}$.

\begin{tabular}{lc}
\hline Clinical characteristic & Value \\
\hline Sex, n (male/female) & $1 / 17$ \\
Age range, years & $15-47$ \\
Range of LN duration, months & $1-26$ \\
SLEDAI & $15-32$ \\
Proteinuria range, g/24 h & $0.27-10.70$ \\
Serum C3 range, mg/dl & $16.0-56.7$ \\
Serum C4 range, mg/dl & $1.2-12.8$ \\
ANA reactivity, $\mathrm{n}$ (positive/negative) & $18 / 0$ \\
Anti-dsDNA reactivity, n (positive/negative) & $13 / 5$ \\
Anti-Sm reactivity, $\mathrm{n}$ (positive/negative) & $11 / 7$ \\
Anti-RNP reactivity, $\mathrm{n}$ (positive/negative) & $11 / 7$ \\
\hline
\end{tabular}

LN, lupus nephritis; SLEDAI, systemic lupus erythematosus disease activity index; ANA, antinuclear antibody; anti-dsDNA, anti-double-stranded DNA antibody; anti-RNP, anti-ribonucleoprotein antibody; anti-Sm, anti-Smith antibody.

reactions were performed in triplicate. Primer sequences and the annealing temperature of BAFF, phosphorylated (p)-PI3K, p-Akt, p-mTOR and reference gene $\beta$-actin are presented in Table II. The $2^{-\Delta \Delta C q}(21)$ method was used to calculate the expression levels of target genes.

Western blotting. Frozen kidney tissue samples were homogenized in a cold radioimmunoprecipitation assay cell lysis buffer (Shanghai Sunred Biological Technology Co., Ltd., Shanghai, China) supplemented with a protease and phosphatase inhibitor cocktail, and phenylmethane sulfonyl fluoride. The crude extract was separated from the debris by centrifugation $\left(800 \mathrm{x} \mathrm{g} ; 10 \mathrm{~min}\right.$ at $\left.4^{\circ} \mathrm{C}\right)$ and the supernatant was separated by centrifugation $\left(14,000 \mathrm{x} \mathrm{g} ; 15 \mathrm{~min}\right.$ at $\left.4^{\circ} \mathrm{C}\right)$. The cryolysis product was collected and the concentration of purified protein was measured by bicinchoninic acid assay kit (Sigma-Aldrich; Merck KGaA, Darmstadt, Germany). Equal amounts of the protein sample $(50 \mu \mathrm{g})$ were denatured in 4X Laemmli buffer [250 mM tris-hydrochloride ( $\mathrm{pH} 6.8$ ), $40 \%$ glycerol, $8 \%$ SDS, $0.01 \%$ bromphenol blue and $20 \%$ $\beta$-mercaptoethanol] and separated via SDS-PAGE on $10 \%$ gels. Following that, the proteins were transferred onto a nitrocellulose membrane (GE Healthcare, Chicago, IL, USA). Subsequently, the membranes were blocked with $5 \%$ milk at $4^{\circ} \mathrm{C}$ overnight in TBS with Tween-20 (TBS-T) and probed with the primary antibody in TBS-T supplemented with $5 \%$ blocking milk at a dilution of $1: 1,000$. The primary antibodies included: Rabbit anti-BAFF (cat. no. 19944S; Cell Signaling Technology, Inc., Danvers, MA, USA), anti-p-PI3K p85 (Tyr458; cat. no. 3821S; Cell Signaling Technology, Inc.), anti-p-AKT (Thr308; cat. no. 4056S; Cell Signaling Technology, Inc.), anti-p-mTOR (Ser2448; cat. no. 2976S; Cell Signaling Technology, Inc.), anti-GAPDH (cat. no. 2118L; Cell Signaling Technology, Inc.; 1:1,000), and incubated for $2 \mathrm{~h}$ at room temperature. An IRDye ${ }^{\circledR} 800 \mathrm{CW}$ goat anti-mouse antibody (cat. no. 926-32210; LI-COR Biosciences, Lincoln, 
Table II. Primer sequences.

Primer sequence $\left(5^{\prime}-3^{\prime}\right)$

Annealing

temperature,

\begin{tabular}{ll}
\cline { 2 - 2 } Gene & \multicolumn{1}{c}{ Forward } \\
\hline$\beta$-actin & CCTGTACGCCAACACAGTGC \\
BAFF & TCTCCGGGAATCTCTGATGC \\
p-PI3K & TCCCAGGTGGAATGAATGGC \\
p-AKT & GGACAAGGACGGGCACATTA \\
p-mTOR & CTTATGGTGCGGTCCCTTGT
\end{tabular}

Reverse

${ }^{\circ} \mathrm{C}$

$\begin{array}{ll}\text { ATACTCCTGCTTGCTGATCC } & 60 \\ \text { TCTTGGTGGTCACCAGTTCAG } & 60 \\ \text { TTTAGCACCCTTTCGGCCTT } & 60 \\ \text { CGACCGCACATCATCTCGTA } & 60 \\ \text { GGTCACCTGAGGGTGAACTG } & 60\end{array}$

p-PI3K, phosphorylated-phosphoinositide 3-kinase; p-Akt, phosphorylated-protein kinase B; p-mTor, phosphorylated-mammalian target of rapamycin.

NE, USA; 1:10,000) was used as a secondary antibody for $2 \mathrm{~h}$ at room temperature. Proteins were visualized at a wavelength of $800 \mathrm{~nm}$ on an Odyssey Luminescent Image Analysis system (LI-COR Biosciences) and analyzed with ImageJ software version $1.37 \mathrm{v} 51.52$ (National Institutes of Health, Bethesda, MD, USA).

Statistical analysis. SPSS software (version 13.0; SPSS, Inc., Chicago, IL, USA) was used to perform all data analyses. The results were expressed as the mean \pm standard deviation. Differences between the LN and control groups were analyzed using a Mann-Whitney $U$ test. The correlation between BAFF and PI3K/Akt/mTOR signaling was determined using the Spearman's rank correlation coefficient. $\mathrm{P}<0.05$ was considered to indicate a statistically significance difference.

\section{Results}

Clinical characteristics, laboratory results and histological parameters of patients with $L N$. The clinical characteristics and laboratory test data of recruited patients with LN are demonstrated in Table I, and histological parameters are presented in Table III.

Plasma levels of BAFF. The plasma levels of BAFF in patients with LN were increased significantly compared with the controls (584.07 \pm 55.57 vs. $207.73 \pm 29.77$ ng/l; $\mathrm{P}<0.001$; Fig. 1).

Analysis of mRNA expression of BAFF, $p$-PI3K, $p$-Akt and $p$-mTOR in kidney tissues by RT-qPCR. The results of the present study demonstrated that the mRNA expression levels of BAFF, p-PI3K, p-Akt and p-mTOR in kidney tissue of patients with LN were significantly increased compared with the controls (all $\mathrm{P}<0.001$; Fig. 2). The mRNA levels of BAFF in the kidney tissue of patients with LN were positively correlated with the expression levels of p-PI3K, p-Akt and p-mTOR ( $r=0.751,0.810,0.806$; all $\mathrm{P}<0.001$; data not shown).

Analysis of protein expression of BAFF, p-PI3K, p-Akt and $p$-mTOR in kidney tissue by western blotting. The protein expression levels of BAFF were significantly increased compared with the controls, upregulation of p-PI3K, p-AKT and
Table III. Histological parameters of patients with LN.

ISN/RPS classification No. of patients

\section{I}

II

III 3 2

IV 10

$\mathrm{V}$ 0

III+V

$\mathrm{IV}+\mathrm{V}$ 1

LN, lupus nephritis; ISN/RPS, International Society of Nephrology/Renal Pathology Society. The range of the renal tissue activity index was 3-9; the range of the renal tissue chronicity index was $0-3$.

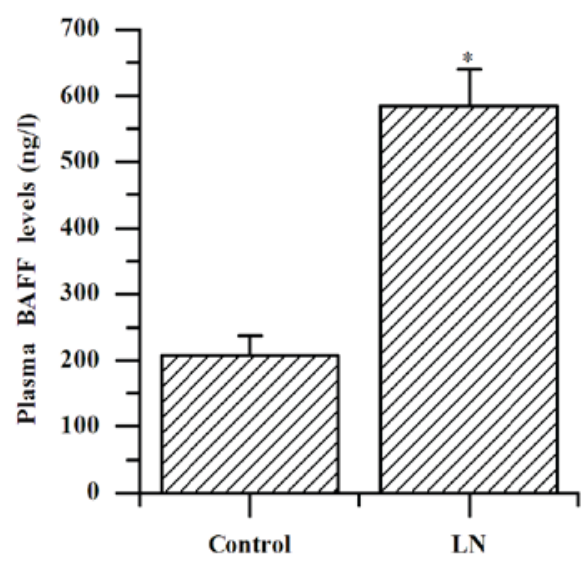

Figure 1. Plasma levels of BAFF in patients with LN and the control group. The data was expressed as the mean \pm standard deviation from two independent experiments. ${ }^{*} \mathrm{P}<0.001$ vs. the control group. LN, lupus nephritis; BAFF, $B$ cell activating factor.

p-mTOR was demonstrated in the patients with LN compared with the control group (all $\mathrm{P}<0.001$; Fig. $3 \mathrm{~A}$ and $\mathrm{B}$ ). The protein levels of BAFF in the kidney tissue of patients with $\mathrm{LN}$ were positively correlated with the expression levels of $\mathrm{p}-\mathrm{PI} 3 \mathrm{~K}$, p-Akt and p-mTOR ( $\mathrm{r}=0.803,0.738,0.798$; all $\mathrm{P}<0.001$; data not 

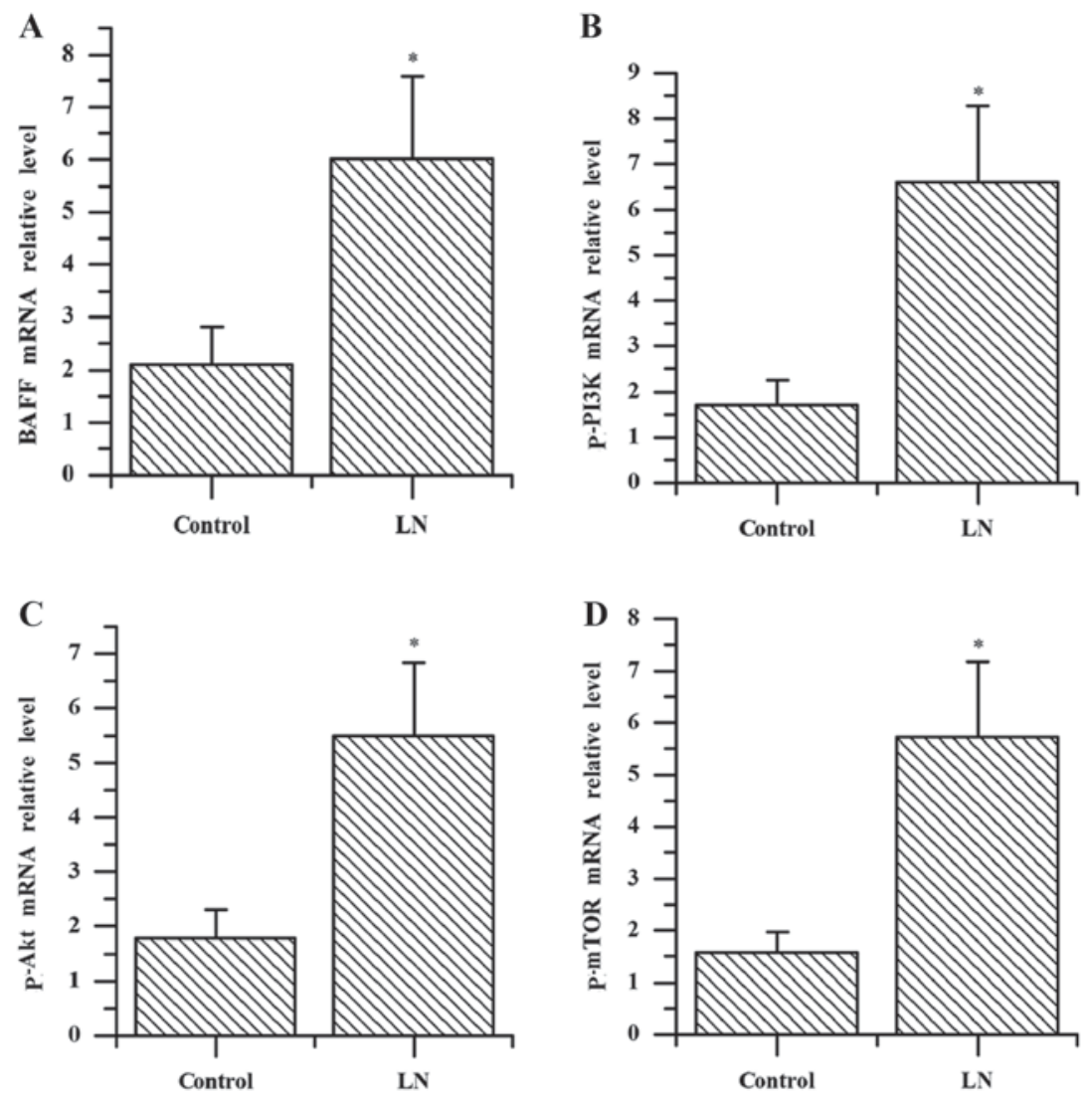

Figure 2. Reverse transcriptase-quantitative polymerase chain reaction quantification of (A) BAFF, (B) p-PI3K, (C) p-AKT, (D) p-mTOR mRNA levels in kidney tissue of the patients with $\mathrm{LN}$ and the control group. The data were expressed as the mean \pm standard deviation from two independent experiments. "P<0.001 vs. the control group. LN, lupus nephritis; BAFF, B cell activating factor; p-PI3K, phosphorylated-phosphoinositide 3-kinase; p-AKT, phosphorylated-protein kinase B; p-mTOR, phosphorylated-mammalian target of rapamycin.

A
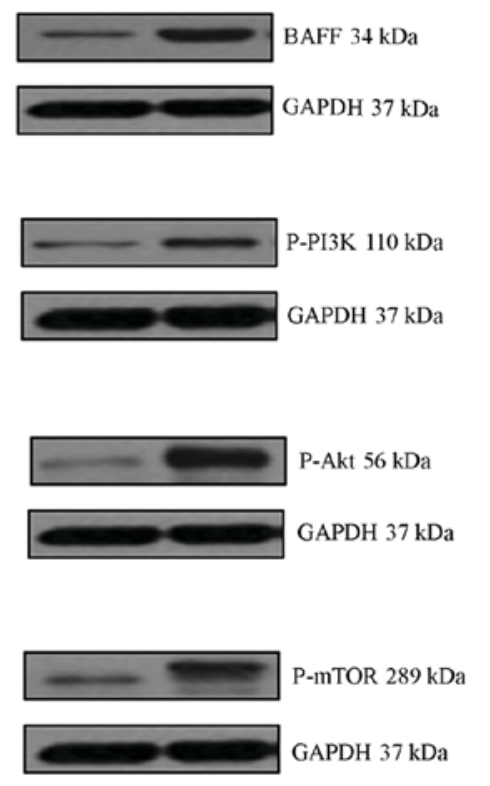

B
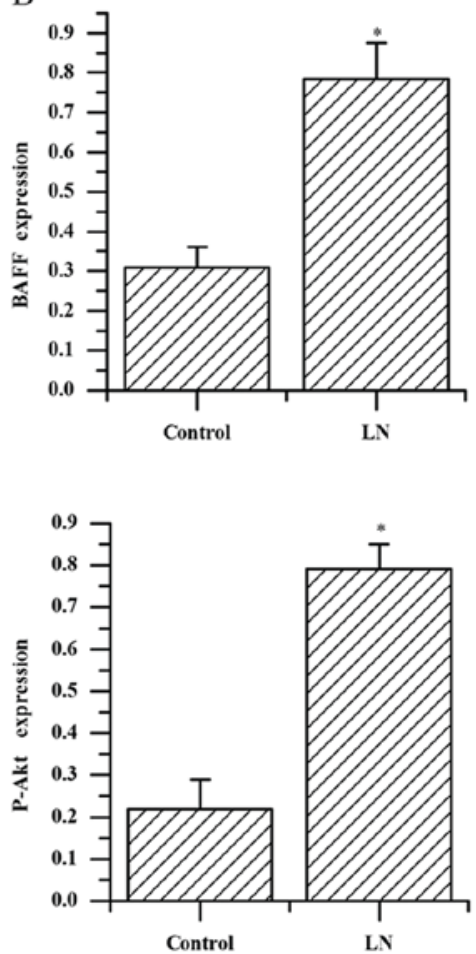
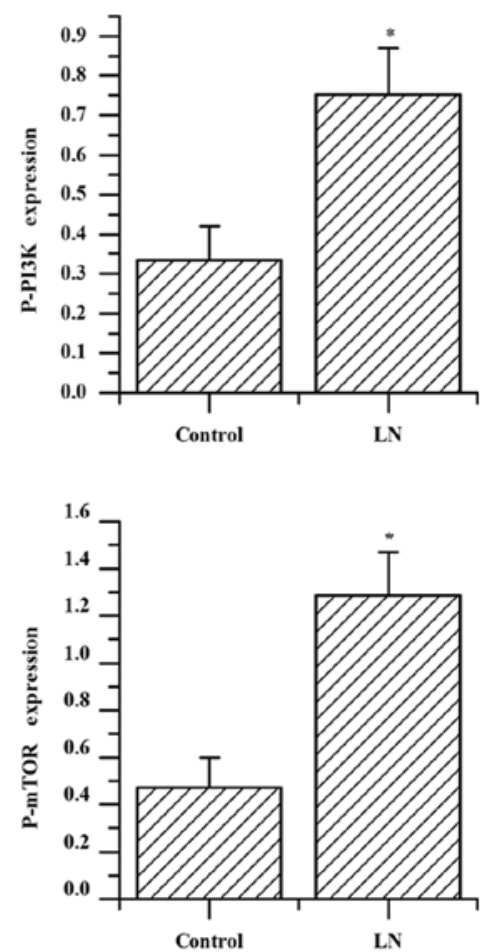

Figure 3. Evaluation of protein expression in the kidney of patients with LN. (A) Expression of BAFF, p-PI3K, p-AKT, p-mTOR was detected by western blot analysis in patients with LN and the control group. (B) Quantified protein levels of BAFF, p-PI3K, p-AKT and p-mTOR. The data was expressed as the mean \pm standard deviation from two independent experiments. " $\mathrm{P}<0.001$ vs. the control group. LN, lupus nephritis; BAFF, B cell activating factor; $\mathrm{p}-\mathrm{PI} 3 \mathrm{~K}$, phosphorylated-phosphoinositide 3-kinase; p-AKT, phosphorylated-protein kinase B; p-mTOR, phosphorylated-mammalian target of rapamycin. 
shown). These results indicate a correlation between BAFF and $\mathrm{PI} 3 \mathrm{~K} / \mathrm{Akt} / \mathrm{mTOR}$ signaling and it is hypothesized that they are involved in the mechanism of LN progression.

\section{Discussion}

LN is a common and serious complication of SLE, which leads to increased mortality and decreased quality of life. The mechanism of LN progression involves activation of polyclonal B cells. BAFF is important to B lymphocyte survival and differentiation. The overexpression of BAFF is correlated with the pathogenesis and development of various autoimmune diseases, including SLE (22). Furthermore, a large number of studies have indicated that the level of BAFF is increased significantly in SLE $(23,24)$, implying that it is a therapeutic target for SLE (25) and therefore BAFF has been indicated as a prognostic marker in SLE. In the present study BAFF levels in the plasma were also elevated in patients with $\mathrm{LN}$. In addition, the mRNA and protein levels of BAFF were elevated in the kidney tissue of patients with LN. These results suggested that BAFF may serve a role in kidney damage in patients with LN.

$\mathrm{PI} 3 \mathrm{~K}$ acts as a signaling molecule that can regulate multiple cellular processes and Akt is a downstream effector of PI3K. p-Akt is frequently formed as a result of PI3K activation. A previous study revealed that B cells, under the influence of BAFF, lead to prolonged phosphorylation of Akt, which serves an essential role in regulating glucose metabolism and cell cycle progression (26). It appears that Akt may be a critical component of BAFF-mediated cellular survival and metabolic fitness. In addition, further evidence demonstrates that the activation of Akt by BAFF stimulation is inhibited by B cells with the PI3K suppressant LY294002 (27,28). Activation of the PI3K/Akt signaling pathway is important in the biological function of normal and aberrant B lymphocytes in B cell receptor signaling and the downstream pathways that regulate cell proliferation, maturation and differentiation (29).

mTOR, a serine/threonine kinase, serves a pivotal role in numerous cellular processes, including cellular proliferation, apoptosis, migration, angiogenesis and protein translation (30). A previous study demonstrated that mTOR possesses extensive and diverse physiological functions, particularly in cell metabolism (31) and could be more appropriately described as an immune regulator (32). BAFF stimulation can result in the activation of mTOR (27) and PI3K/Akt signaling is the primary pathway that regulates mTOR function in immune cells.

The PI3K/Akt/mTOR pathway contributes to a broad range of biological processes including the cell cycle, glucose metabolism and protein synthesis. An early study demonstrated that $B$ cells with protein kinase $C-\beta$ deficiency exhibit altered phosphorylation of Akt and restriction of cell growth when stimulated by BAFF, and this demonstrated the significance of the PI3K/Akt/mTOR signaling pathway in BAFF-mediated B cell growth (28). PI3K/AKT/mTOR signaling can provide $\mathrm{B}$ cells with resistance to apoptosis by increasing the level of Bcl-2, leading to decreased cellular metabolism in B cells (20).

The present study demonstrated that the expression of BAFF was increased significantly in patients with LN. In comparison with the controls, the results of RT-qPCR and western blotting demonstrated that the expression levels of p-PI3K, p-Akt and p-mTOR increased in patients with LN. Furthermore, mRNA and protein levels of BAFF in kidney tissue of patients with LN were positively correlated with the levels of p-PI3K, p-Akt and p-mTOR. The results of the present study indicated that BAFF may be a crucial upstream mediator of the PI3K/Akt/mTOR signaling pathway in response to B cell activation. The present study demonstrated a correlation between BAFF and the PI3K/Akt/mTOR pathway and hypothesized that they are involved in the pathogenesis of $\mathrm{LN}$ in patients.

In recent years, belimumab, a BAFF inhibitor, has been developed which provides a promising, novel avenue for the treatment of SLE and contributes to the progress of therapy development. Meta-analysis indicates that combination therapy with belimumab and the standard treatment is safer and more effective in patients with SLE compared with using the standard therapy alone (33). Furthermore, the PI3K/Akt/mTOR pathway inhibitors were investigated to explore their mode of action and therapeutic use against malignant tumors (34-36) and have not been studied in patients with SLE and LN. The present study revealed a correlation between BAFF and the PI3K/Akt/mTOR pathway in patients with LN. As humans were used in the present study, ethically they could not be treated with BAFF and PI3K/Akt/mTOR pathway inhibitors. Therefore, animal experiments would be required in the future to confirm whether BAFF is involved in the mechanism of $\mathrm{LN}$ through regulation of the $\mathrm{PI} 3 \mathrm{~K} / \mathrm{Akt} / \mathrm{mTOR}$ pathway, which may provide guidance for the development of novel and effective therapies for patients with $\mathrm{LN}$.

\section{Acknowledgements}

The present study was funded by the Binzhou City Science and Technology Development Program (grant no. 2014ZC0142), and the Binzhou Medical University of Science and Technology Plan Project (grant no. BY2013KJ29).

\section{References}

1. Crispín JC, Kyttaris VC, Terhorst C and Tsokos GC: T cells as therapeutic targets in SLE. Nat Rev Rheumatol 6: 317-325, 2010.

2. De Zubiria Salgado A and Herrera-Diaz C: Lupus nephritis: An overview of recent findings. Autoimmune Dis 2012: 849684, 2012.

3. Tsokos GC: Systemic lupus erythematosus. N Engl J Med 365: 2110-2121, 2011.

4. Shen Y, Sun CY, Wu FX, Chen Y, Dai M, Yan YC and Yang CD: Association of intrarenal B-cell infiltrates with clinical outcome in lupus nephritis: A study of 192 cases. Clin Dev Immunol 2012: 967584, 2012.

5. Sun CY, Shen Y, Chen XW, Yan YC, Wu FX, Dai M, Li T and Yang CD: The characteristics and significance of locally infiltrating B cells in lupus nephritis and their association with local BAFF expression. Int J Rheumatol 2013: 954292, 2013.

6. Heinemann K, Wilde B, Hoerning A, Tebbe B, Kribben A, Witzke O and Dolff S: Decreased IL-10(+) regulatory B cells (Bregs) in lupus nephritis patients. Scand J Rheumatol 45: 312-316, 2016.

7. Schneider P and Tschopp J: BAFF and the regulation of B cell survival. Immunol Lett 88: 57-62, 2003.

8. Mackay F and Browning JL: BAFF: A fundamental survival factor for B cell. Nat Rev Immunol 2: 465-475, 2002.

9. Schneider P, MacKay F, Steiner V, Hofmann K, Bodmer JL, Holler N, Ambrose C, Lawton P, Bixler S and Acha-Orbea H: BAFF, a novel ligand of the tumor necrosis factor family, stimulates B cell growth. J Exp Med 189: 1747-1756, 1999. 
10. Mayne CG, Amanna IJ, Nashold FE and Hayes CE: Systemic autoimmunity in BAFF-R-mutant A/WySnJ strain mice. Eur J Immunol 38: 587-598, 2008.

11. Mackay F and Schneider P: Cracking the BAFF code. Nat Rev Immunol 9: 491-502, 2009.

12. Thien M, Phan TG, Gardam S, Amesbury M, Basten A, Mackay F and Brink R: Excess BAFF rescues self-reactive B cells from peripheral deletion and allows them to enter forbidden follicular and marginal zone niches. Immunity 20: 785-798, 2004.

13. Gross JA, Johnston J, Mudri S, Enselman R, Dillon SR, Madden K, Xu W, Parrish-Novak J, Foster D and Lofton-Day C: TACI and BCMA are receptors for a TNF homologue implicated in B-cell autoimmune disease. Nature 404: 995-999, 2000.

14. Khare SD, Sarosi I, Xia XZ, McCabe S, Miner K, Solovyev I, Hawkins N, Kelley M, Chang D and Van G: Severe B cell hyperplasia and autoimmune disease in TALL-1 transgenic mice. Proc Natl Acad Sci USA 97: 3370-3375, 2000.

15. Moore PA, Belvedere O, Orr A, Pieri K, LaFleur DW, Feng P, Soppet D, Charters M, Gentz R and Parmelee D: BLyS: Member of the tumor necrosis factor family and B lymphocyte stimulator. Science 285: 260-263, 1999.

16. Henley T, Kovesdi D and Turner M: B-cell responses to $\mathrm{B}$-cell activation factor of the TNF family (BAFF) are impaired in the absence of PI3K delta. Eur J Immunol 38 3543-3548, 2008.

17. Shor B, Cavender D and Harris C: A kinase-dead knock-in mutation in mTOR leads to early embryonic lethality and is dispensable for the immune system in heterozygous mice. BMC Immunol 10: 28, 2009.

18. Fruman DA: Phosphoinositide 3-kinase and its targets in B-cell and T-cell signaling. Curr Opin Immunol 16: 314-320, 2004.

19. Li PP, Liu DD, Liu YJ, Song SS, Wang QT, Chang Y, Wu YJ, Chen JY, Zhao WD, Zhang LL and Wei W: BAFF/BAFF-R involved in antibodies production of rats with collagen-induced arthritis via PI3K-Akt-mTOR signaling and the regulation of paeoniflorin. J Ethnopharmacol 141: 290-300, 2012.

20. Liu D, Li P, Song S, Liu Y, Wang Q, Chang Y, Wu Y, Chen J, Zhao W, Zhang L and Wei W: Pro-apoptotic effect of epigallo-catechin-3-gallate on B lymphocytes through regulating $\mathrm{BAFF} / \mathrm{PI} 3 \mathrm{~K} / \mathrm{Akt} / \mathrm{mTOR}$ signaling in rats with collagen-induced arthritis. Eur J Pharmacol 690: 214-225, 2012.

21. Livak KJ and Schmittgen TD: Analysis of relative gene expression data using real-time quantitative PCR and the 2(-Delta Delta C(T)) method. Methods 25: 402-408, 2001.

22. Vincent FB, Morand EF, Schneider $\mathrm{P}$ and Mackay $\mathrm{F}$ : The BAFF/APRIL system in SLE pathogenesis. Nat Rev Rheumatol 10: 365-373, 2014.
23. Salazar-Camarena DC, Ortiz-Lazareno PC, Cruz A, Oregon-Romero E, Machado-Contreras JR, Muñoz-Valle JF, Orozco-López M, Marín-Rosales M and Palafox-Sánchez CA: Association of BAFF, APRIL serum levels, BAFF-R, TACI and BCMA expression on peripheral B-cell subsets with clinical manifestations in systemic lupus erythematosus. Lupus 25: 582-592, 2016.

24. Figgett WA,DeliyantiD,Fairfax KA, QuahPS, Wilkinson-BerkaJL and Mackay F: Deleting the BAFF receptor TACI protects against systemic lupus erythematosus without extensive reduction of $B$ cell numbers. J Autoimmun 61: 9-16, 2015.

25. Jordan N and D'Cruz DP: Belimumab for the treatment of systemic lupus erythematosus. Expert Rev Clin Immunol 11: 195-204, 2015.

26. Debnath I, Roundy KM, Weis JJ and Weis JH: Analysis of the regulatory role of BAFF in controlling the expression of $\mathrm{CD} 21$ and CD23. Mol Immunol 44: 2388-2399, 2007.

27. Woodland RT, Fox CJ, Schmidt MR, Hammerman PS, Opferman JT, Korsmeyer SJ, Hilbert DM and Thompson CB: Multiple signaling pathways promote B lymphocyte stimulator dependent B-cell growth and survival. Blood 111: 750-760, 2008.

28. Patke A, Mecklenbräuker I, Erdjument-Bromage H, Tempst P and Tarakhovsky A: BAFF controls B cell metabolic fitness through a PKC beta- and Akt-dependent mechanism. J Exp Med 203: 2551-2562, 2006.

29. Blachly JS and Baiocchi RA: Targeting PI3-kinase (PI3K), AKT and mTOR axis in lymphoma. Br J Haematol 167: 19-32, 2014.

30. Laplante M and Sabatini DM: mTOR signaling in growth control and disease. Cell 149: 274-293, 2012.

31. Shimobayashi M and Hall MN: Making new contacts: The mTOR network in metabolism and signalling crosstalk. Nat Rev Mol Cell Biol 15: 155-162, 2014.

32. Thomson AW, Turnquist HR and Raimondi G: Immunoregulatory functions of mTOR inhibition. Nat Rev Immunol 9: 324-337, 2009.

33. Wei LQ, Liang YG, Zhao Y, Liang HT, Qin DC and She MC: Efficacy and safety of belimumab plus standard therapy in patients with systemic lupus erythematosus: A meta-analysis. Clin Ther 38: 1134-1140, 2016.

34. Asati V, Mahapatra DK and Bharti SK: PI3K/Akt/mTOR and Ras/Raf/MEK/ERK signaling pathways inhibitors as anticancer agents: Structural and pharmacological perspectives. Eur J Med Chem 109: 314-341, 2016.

35. Lee JJ, Loh K and Yap YS: PI3K/Akt/mTOR inhibitors in breast cancer. Cancer Biol Med 12: 342-354, 2015.

36. Soares HP, Ming M, Mellon M, Young SH, Han L, Sinnet-Smith J and Rozengurt E: Dual PI3K/mTOR inhibitors induce rapid overactivation of the MEK/ERK pathway in human pancreatic cancer cells through suppression of mTORC2. Mol Cancer Ther 14: 1014-1023, 2015. 